\title{
Primary malignant melanoma of vagina: a case report
}

\author{
Smruti Gedam ${ }^{1}$, Tarachand Sharma ${ }^{2 *}$
}

\begin{abstract}
${ }^{1}$ Department of Obstetrics and Gynecology, Government Medical College and Hospital, Nagpur, Maharashtra, India ${ }^{2}$ Department of Obstetrics and Gynecology, Grant Medical College and JJ Group of Hospitals, Mumbai, Maharashtra, India
\end{abstract}

Received: 08 June 2020

Accepted: 08 July 2020

\section{*Correspondence:}

Dr. Tarachand Sharma,

E-mail: drtarachandsharma@rediffmail.com

Copyright: ( $)$ the author(s), publisher and licensee Medip Academy. This is an open-access article distributed under the terms of the Creative Commons Attribution Non-Commercial License, which permits unrestricted non-commercial use, distribution, and reproduction in any medium, provided the original work is properly cited.

\begin{abstract}
Primary malignant melanoma of the vagina is a rare and aggressive disease with worse prognosis as compared with non-genital melanomas or other vaginal malignant neoplasms. Presented here is a case of 42 years female with 3 months history of amenorrhea and vaginal discharge. On vaginal examination, a firm growth of size approximately 7 $8 \mathrm{~cm}$ was found attached to the left postero-lateral wall of vagina and extending up to the introitus. On biopsy and histopathological examination, it was diagnosed as a case of high-grade malignant melanoma of amelanotic type. Radiotherapy was started as a part of treatment after consultation with an oncologist, considering non-resectable nature of the mass. The patient received first 5 cycles of radiotherapy but succumbed to the disease during treatment.
\end{abstract}

Keywords: Amelanotic melanoma, Primary malignant melanoma, Vaginal melanoma

\section{INTRODUCTION}

Malignant melanoma of vagina is a rare tumour with an incidence of only 0.46 cases per one million women per year, with less than 300 cases having been documented in literature till date. ${ }^{1-3}$ It accounts for less than $1 \%$ of all malignant melanomas and less than $3 \%$ of all primary malignant tumours of the vagina. ${ }^{4}$ This aggressive and almost always invasive tumour has a poor prognosis with 5 year survival rate ranging from 5-25\%.4-6 It usually occurs in postmenopausal women in their 60 s and 70 s, with the optimal treatment being a subject of constant debate. ${ }^{7}$ Authors present a case of 42 years premenopausal patient with primary malignant melanoma presenting at a tertiary care government hospital.

\section{CASE REPORT}

A 42 years female patient (para 1, live 1) reported at our out-patient department, with history of 3 months of amenorrhea and vaginal discharge, which turned purulent since last one month. Other recent and seemingly unrelated complaint was pain in left hip joint. The patient was initially consulting at a private hospital for 3 weeks before reaching our hospital. The first examination done in the previous hospital had revealed foul smelling vaginal discharge and e/o exophytic growth involving cervix and vagina, with the rectal mucosa being free. Local biopsy was also done there and the histopathological report was found to be suggestive of papillary squamous hyperplasia. Ultrasound of pelvis done at that time was showing heterogeneously hypoechoic mass lesion in cervical region extending into lower vagina $(5.1 \times 6.4 \times 6.8 \mathrm{~cm})$ with right adnexa has a mass lesion of $4.4 \times 2 \mathrm{~cm}$. The patient was prescribed a course of empirical antibiotics.

Examination at authors' OPD showed soft abdomen with no mass palpable. Speculum examination could not be done as vagina was very narrow and it was painful, but foul-smelling discharge was observed. Per vaginal examination could be done with single finger only and revealed evidence of large bulky proliferative mass lesion involving lower part of posterior and lateral walls of 
vagina just short of introitus, firm to hard in consistency with smooth surface, not bleeding upon touch. Bilateral parametria were found to be involved. Uterus and cervix could not be commented upon. Per rectally, large, approximately $7.0 \times 7.0 \mathrm{~cm}$ mass was felt through the anterior wall of rectum and anal canal with rectal mucosal involvement. With these findings, the patient was admitted with provisional diagnosis of (?) carcinoma vagina/(??) carcinoma cervix, (stage IV). Basic investigations were done and the treatment was started on injectable antibiotics. Further, MRI of abdomen and pelvis was done, which was suggestive of large lobulated heterogeneous partly necrotic neoplastic lesion, approximately $11.0 \times 7.5 \times 6.5 \mathrm{~cm}$ in dimensions, in mid and lower vagina which significantly distended vagina. Superiorly the lesion was seen projecting into upper vagina as well. The lesion protruded into lumen of lower rectum and anal canal posteriorly. Uterus measured $6.6 \times 4.5 \times 2.7 \mathrm{~cm}$ with endometrial cavity and junctional zone, cervix, endocervical canal and cervical stroma being uninvolved. Enlarged right iliac lymph nodes and few small external iliac nodes were observed to be affected and appeared to be metastatic in nature. Focal marrow abnormality observed along the posterior column of left acetabulum was also suspicious of skeletal metastasis. Small nodule $(9 \mathrm{~mm})$ on left adrenal gland was also reported. Chest radiograph showed minimal non-tapable pleural effusion on right side. Oncologist opinion was sought at this point and local excisional biopsy was planned. Histopathology report at our centre revealed high grade malignant melanoma of vagina (amelanotic type). Considering the tissue diagnosis, rapid growth, progressed stage and spread of the tumour, radiotherapy was planned as combined opinion from gynecologist and oncologist. Radiotherapy was planned and the patient received first 5 cycles of External beam radiation therapy (EBRT) with palliative intent (40 Gy in 10 fractions; 2 fractions per week) at the study hospital, but she could not tolerate it and succumbed to death within 4 weeks of diagnosis.

\section{DISCUSSION}

Primary malignant melanoma is an extremely rare and lethal entity first reported by Poronas in 1887 and the incidence has remained largely unchanged since 1980s. ${ }^{8}$ The tumour typically presents in the sixth and seventh decades of life and occurs more commonly in the lower $1 / 3^{\text {rd }}$ of the vagina, mostly in the anterior vaginal wall, in contrast to squamous cell carcinoma where lesions are seen mostly in upper one third of posterior vaginal wall. ${ }^{4}$ It usually affects post- menopausal women and does not have any known risk factors. ${ }^{9}$ If primary vaginal malignancy is found in younger women, it may be etiologically related to cervical cancer, more specifically to the persistence of high risk HPV infection. The case presented here was that of a 42 years old, sexually active female with no known risk factors, but the mentioned possibility of HPV infection could not be ruled out. The most common symptoms are vaginal bleeding, vaginal discharge and feeling a mass in the vagina. ${ }^{4}$ Grossly, the tumour is polypoid to nodular in the majority of cases. ${ }^{10}$ The appearance of the tumour is almost always pigmented and only $10-23 \%$ are amelanotic, like in present case. $^{11}$ Primary vaginal cancer needs to be differentiated from poorly differentiated squamous cell carcinoma, sarcoma, lymphoma, blue nevus, cancer cervix and cancers metastatic to vagina, which constitute the majority of vaginal cancers $(80 \%$ to $90 \%) .{ }^{12}$ It is strictly defined as a cancer found in the vagina without clinical or histological evidence of cervical or vulvar cancer or prior history of these cancers within last five years.

The natural course of malignant melanomas is marked by early local recurrence, extensions and frequent metastases to the lymph nodes, viscera along with possibility of life threatening hemorrhage, making it the most dangerous form of vaginal tumour with high rate of recurrence and poor long term survival. ${ }^{13,14}$ Clinical staging of primary mucosal melanomas is based on guidelines by the International Federation of Gynecology and Obstetrics (FIGO), while pathological staging is based on the American Joint Committee on Cancer's (AJCC) TNM staging method. ${ }^{15,16}$ TNM has been typically used for staging skin cancer lesions; however, due to its detailed staging system and prognosis prediction, Seifried et al, reported it to be a better staging system for malignant vulva and vaginal melanomas. ${ }^{17}$ Although the management is primarily guided by the staging of the disease, surgery (wide local excision or radical surgery) remains the preferred treatment for resectable masses and is almost always considered first. ${ }^{17,18}$ Wide excision may be wide radical excision or wide local excision where less than $2 \mathrm{~cm}$ circumferential margin is obtained because of difficult anatomic location of tumour. ${ }^{7}$ Surgical treatment is traditionally found to be positively associated with prolonged survival when compared to other treatment methods. $^{18,19}$ Optimal treatment (radical surgery or radiotherapy) for an individual patient has been a matter of controversy. Since distant metastases are a component in majority of recurrence, adjuvant systemic therapy might be warranted in these high-risk cases. ${ }^{20}$ In the present case, as the mass was non-resectable at the time of diagnosis, radiotherapy was planned the modality of therapy. The literature does favor radiotherapy to be offered as a treatment regime if the patient is unfit for surgical intervention or preoperatively as adjuvant treatment for tumor shrinkage or postoperatively as adjuvant treatment in cases of incomplete tumor resection or with pelvic metastases. ${ }^{18-20}$ Apart from these established treatment approaches, multiple traditional cytotoxic agents, including dacarbazine, temozolomide, and platinum compounds, nitrosoureas and taxanes, both as single agents and in combination, have been evaluated in the treatment of melanoma, with limited or no success. The response rate of these single agent is $11-22 \%$ with median overall survival of 5.6-11 months. ${ }^{7}$ The prognosis of vaginal melanoma is very poor, regardless the 
treatment modality, as most cases are diagnosed at a late stage.

\section{CONCLUSION}

In conclusion, primary malignant vaginal melanoma is a rare but aggressive and lethal entity. The most accepted treatment of malignant melanoma of the vagina is surgery and adjuvant radiotherapy on a case to case basis. The survival rate is largely dependent on nodal and distant metastasis of the disease after initial tumor resection. There is dire need and strong recommendation towards formation of a proper therapeutic regime to control the disease.

Funding: No funding sources

Conflict of interest: None declared

Ethical approval: Not required

\section{REFERENCES}

1. $\mathrm{Hu} \mathrm{DN}, \mathrm{Yu}$ GP, McCormick SA. Population-based incidence of vulvar and vaginal melanoma in various races and ethnic groups with comparisons to other site-specific melanomas. Melanoma Res. 2010;20(2):153-8.

2. Fulciniti F, Ascierto PA, Simeone E, Bove P, Losito S, Russo S, et al. Nevoid melanoma of the vagina: report of one case diagnosed on thin layer cytological preparations. Cyto J. 2007;4:14.

3. Piura B, Rabinovich A, Yanai-Inbar I. Primary malignant melanoma of the vagina: case report and review of literature. Eur $\mathbf{J}$ Gynaecol Oncol. 2002;23(3):195-8.

4. Samolis S, Panagopoulos P, Kanellopoulos N, Papastefanou I, Karadaglis S, Katsoulis M. Primary melanoma of the vagina: a case report. Eur J Gynaecol Oncol. 2010;31(2):233-4.

5. Frumovitz M, Etchepareborda M, Sun CC, Soliman PT, Eifel PJ, Levenback CF, et al. Primary malignant melanoma of the vagina. Obstet Gynecol. 2010;116(6):1358-65.

6. Tjalma WA, Monaghan JM, Naik R, Nordin A. Primary vaginal melanoma and long-term survivors. Eur J Gynaecol Oncol. 2001;22(1):20-2.

7. Lin LT, Liu CB, Chen SN, Chiang AJ, Liou WS, Yu KJ. Primary malignant melanoma of the vagina with repeated local recurrences and brain metastasis. J Chinese Med Associat. 2011;74(8):376-9.

8. Mino RA, Mino VH, Livingstone RG. Primary melanoma of the vagina, with a review of the literature. Am J Obstet Gynecol. 1948;56(2):325-34.

9. Baloglu A, Bezircioglu I, Cetinkaya B, Yavuzcan A. Primary malignant melanoma of the vagina. Arch Gynecol Obstet. 2009;280(5):819-22.
10. Gupta D, Malpica A, Deavers MT, Silva EG. Vaginal melanoma: a clinicopathologic and immunohistochemical study of 26 cases. The Am J Surg Pathol. 2002;26(11):1450-7.

11. Reid GC, Schmidt RW, Roberts JA, Hopkins MP, Barrett RJ, Morley GW. Primary melanoma of the vagina: a clinicopathologic analysis. Obstet Gynecol. 1989;74(2):190-9.

12. Chaudhuri S, Das D, Chowdhury S, Gupta AD. Primary malignant melanoma of the vagina: A case report and review of literature. South Asian J Cancer. 2013;2(1):4.

13. McKinnon JG, Kokal WA, Neifeld JP, Kay S. Natural history and treatment of mucosal melanoma. J Surg Oncol. 1989;41(4):222-5.

14. Moros ML, Ferrer FP, Mitchell MJ, Romeo JA, Lacruz RL. Primary malignant melanoma of the vagina: poor response to radical surgery and adjuvant therapy. Eur J Obstet Gynecol Reprod Biol. 2004;113(2):248-50.

15. Benedet JL, Pecorelli S, Ngan HY, Hacker NF, Denny L, Jones III HW, et al. Staging classifications and clinical practice guidelines for gynaecological cancers. Int J Gynecol Obstet. 2000;70:207-312.

16. Edge SB, Compton CC. The American Joint Committee on Cancer: the $7^{\text {th }}$ edition of the AJCC cancer staging manual and the future of TNM. Annals Surg Oncol. 2010;17(6):1471-4.

17. Seifried S, Haydu LE, Quinn MJ, Scolyer RA, Stretch JR, Thompson JF. Melanoma of the vulva and vagina: principles of staging and their relevance to management based on a clinicopathologic analysis of 85 cases. Annals Surg Oncol. 2015;22(6):1959-66.

18. Kirschner AN, Kidd EA, DeWees T, Perkins SM. Treatment approach and outcomes of vaginal melanoma. Int J Gynecol Cancer. 2013;23(8):1484-9.

19. Leitao MM, Cheng X, Hamilton AL, Siddiqui NA, Jurgenliemk-Schulz I, Mahner S, et al. Gynecologic Cancer InterGroup (GCIG) consensus review for vulvovaginal melanomas. Int $\mathbf{J}$ Gynecol Cancer. 2014;24(Supp 3):S117-22.

20. Piura B. Management of primary melanoma of the female urogenital tract. The Lancet Oncol. 2008;9(10):973-81.

Cite this article as: Gedam S, Sharma T. Primary malignant melanoma of vagina: a case report. Int $\mathrm{J}$ Reprod Contracept Obstet Gynecol 2020;9:3499-501. 